\title{
EXPLORING THE IMPORTANCE OF IDENTITY FOLLOWING ACQUIRED BRAIN INJURY:
}

\author{
A REVIEW OF THE LITERATURE
}

\author{
David Segal
}

\begin{abstract}
Life following acquired brain injury (ABI) for survivors and their families is often accompanied by experiences of tremendous physical and emotional difficulties. Upon returning home from in-patient rehabilitation, many survivors struggle to maintain their intimate relationships, come to terms with their injuries, and ultimately build satisfying lives. Addressing the loss and reconstruction of identity for survivors and their families is emerging as a crucial component of rehabilitation following injury. This paper reviews the literature surrounding these phenomena from a social neuropsychology, cognitivepsychological, and psychosocial perspective. In doing so, the epistemological tensions between these perspectives are uncovered and examined. Finally, a summary of post-hospitalization strategies for addressing identity loss and (re)construction for both ABI survivors and their families are provided.
\end{abstract}

Acquired brain injury (ABI) is a serious concern for survivors, their families, and communities. Although technological advancements have increased our ability to screen for injury, locate precise areas of damage through MRI and neuropsychology testing, and encourage the development of new neural pathways, substantial regeneration of neurons is still a distant dream. Thus, practitioners supporting people with ABI are tasked with the difficult job of assisting individuals, their families, and communities in a lengthy process of "recovery" that takes place long after the initial exterior wounds of the injury have healed. Ironically, the majority of attention regarding ABI research and clinical intervention has been devoted to the acute care and management of the injury from a strictly biological perspective. This is despite recognition from families, friends, and community agencies that support is drastically needed in the years following the injury, specifically in areas pertaining to psychosocial development.

One such area emerging in the literature is the concept of identity loss following ABI. Thus, the focus of this paper is to present a literature review pertaining to the experience of loss of identity or "personality change" following ABI for adult survivors.

\footnotetext{
${ }^{1}$ Identity loss and personality change have been used interchangeably to describe the experience of a disparity between how the survivor of an ABI experiences themselves post-injury, compared to pre-injury. Considerable attention will be devoted below to clarifying the differences between these terms and their associated epistemological underpinnings.
} 
Although there are numerous factors to consider when serving people with ABI, the issue of identity is emerging from its previously neglected position among rehabilitation professionals as a pivotal area of concern for survivors and (Ben-Yishay, 2008) and their families (Landau \& Hissett, 2008). There is now mounting support suggesting that in the aftermath of ABI, individuals undergo a profound change in their current experience of themselves compared to pre-injury and this brings forth tremendous discomfort (e.g., Ben-Yishey et al., 1985; Myles, 2004; Nochi, 1997).

This literature review focuses on adult populations, as attempts to include the literature on children and youth presented too broad a scope for this paper. However, many of the concepts discussed are applicable for child and youth populations. Following a brief overview of the profound impact that ABI has on survivors, their families, and communities, I will attempt to answer the following questions:

1. Why has identity been overlooked in the past by rehabilitation professionals?

2. Why is identity an important component of rehabilitation?

3. How do biological, psychological, and social perspectives explain experiences of socalled personality change?

4. What are some clinical interventions being used to address these issues?

\section{Methodology}

The original topic for this literature review was the experiences of identity change for ABI survivors following injury. Key words used for this search were: Acquired Brain Injury and Identity and the databases Medline, Psychinfo, PsychAbstracts, EBSCO, Web of Science, and Academic Search Complete were used to conduct the search. Initial results were too limited so the search was expanded with the same databases using the following key words:

- Acquired Brain Injury

- Traumatic Brain Injury

- Identity loss

- Self

- Self-concept

- Personality

- Narratives

Searches using combinations as well as singular key words were conducted. Moreover, additional sources were located by using reference lists from relevant articles. A recent literature review was conducted on the topic of ABI and identity by Yeates, Gracey, and McGrath (2008) entitled, A biopsychosocial deconstruction of "personality change" following acquired brain injury. Yeates et al. (2008) use a biopsychosocial framework to investigate the topic of identity change. This is a useful framework, as it allows for the inclusion of different perspectives alongside dominant medical and neuropsychological understandings of personality change found in the rehabilitation literature (Myles, 2004). In addition to commenting on the aforementioned literature 
review, additional sources that were omitted or newly published are included in this review.

\section{Unpacking “Personality Change” Following an Acquired Brain Injury}

\section{Acquired Brain Injury: A Grim Prognosis}

According to the World Health Organization (1996), acquired brain injury is defined as "damage to the brain, which occurs after birth and is not related to a congenital or a degenerative disease. These impairments may be temporary or permanent and cause partial or functional disability or psychosocial difficulties" (as cited in B.C. Brain Injury, 2009, p. 3). This definition has been adopted in the Province of British Columbia (B.C. Brain Injury, 2009). As of 2007, approximately 160,000 British Columbians were living with the impacts of acquired brain injury and 14,000 people in the province were expected to acquire new brain injuries by the end of the year (B.C. Brain Injury, 2009). Acquired Brain Injury is highly idiosyncratic and involves changes to biological, cognitive, emotive, and social functioning, ranging in severity depending on the extent and location of injury, age, premorbid personality, and individual social circumstances, e.g., family support, access to rehabilitation services, etc. (Lezak, Howieson, Loring, Hannay, \& Fischer, 2004). ABI is the most common cause of brain damage in children and young adults, with most accidents occurring between ages 15 to 24 (particularly in the first five years) and for the elderly (Lezak et al., 2004). Falls account for half of all injuries for young children and the elderly, and motor vehicle accidents account for more than half of all head injuries in other age groups (Lezak et al., 2004). Mild $\mathrm{ABI}^{2}$ makes up the majority of cases, with moderate cases accounting for $8 \%$ to $10 \%$, and severe cases accounting for fewer than $10 \%$. Although the severe and moderate categories make up a relatively small percentage, "these groups represent a major and growing social problem, because their rehabilitation needs are so great and so costly, because so few return to fully independent living, and because their disabilities create severe financial and emotional burdens for their families" (Lezak et al., 2004, p.179). Potential changes following ABI are presented in Table 1.

\footnotetext{
2 Estimates of severity of acquired brain injury are determined by the length of post-traumatic amnesia duration, e.g., 5 to 60 minutes is considered mild, and 1 to 7 days is considered severe (Lezak et al., 2004).
} 
Table 1. Potential changes following ABI

Physical

Cognitive
Behavioural

\begin{tabular}{|c|c|c|}
\hline $\begin{array}{l}\text { Sensory/perceptual problems: } \\
\text { Double vision } \\
\text { Photophobia } \\
\text { Dizziness } \\
\text { Deafness and/or tinnitus } \\
\text { Headache } \\
\text { Vision impairment } \\
\text { Motor problems: } \\
\text { Coordination of movements } \\
\text { Ataxia } \\
\text { Involuntary eye-movement } \\
\text { Paralysis } \\
\text { Weakness } \\
\text { Numbness } \\
\text { Structural: } \\
\text { Limb shortening } \\
\text { Weight gain } \\
\text { Muscle atrophy }\end{array}$ & $\begin{array}{l}\text { Slowed reaction time } \\
\text { Slowed processing } \\
\text { Poor concentration } \\
\text { Memory problems } \\
\text { Difficulty with retrieval of } \\
\text { information } \\
\text { Confusion } \\
\text { Disorientation } \\
\text { Inability to think clearly } \\
\text { Compromised spatial learning } \\
\text { Compromised executive functions }\end{array}$ & $\begin{array}{l}\text { Heightened distractibility } \\
\text { Difficulty multi-tasking } \\
\text { Emotional distress } \\
\text { Fatigue } \\
\text { Automatic activities become effortful } \\
\text { Heightened irritability } \\
\text { Depression and anxiety } \\
\text { Sleep disturbances } \\
\text { Low self-confidence } \\
\text { Diminished initiative } \\
\text { Affective flattening } \\
\text { Impulsivity } \\
\text { Planning ability and automatic self-monitoring are } \\
\text { frequently compromised } \\
\text { Diminished or heightened sexual desire } \\
\text { Social isolation } \\
\text { Empathy and self-reflective or self-critical attitudes are } \\
\text { greatly diminished } \\
\text { Impaired capacity for self-control } \\
\text { Unpredictable behaviour } \\
\text { Inability to profit from experience compromises the } \\
\text { capacity for social learning } \\
\text { Lowered self-awareness }\end{array}$ \\
\hline
\end{tabular}

(Adapted from Lezak et al., 2004).

Not surprisingly, life for survivors and their families following acquired brain injury is often accompanied by experiences of tremendous physical, emotional, and psychosocial difficulties. Upon returning home from in-patient rehabilitation, many struggle to maintain their intimate relationships (Condeluci, Ferris, \& Bogdan, 1992), come to terms with their injuries (Corrigan, Bogner, \& Mysiw, 2001; Gan, Campbell, Gemeinhardt, \& McFadden, 2006) and arrive at satisfactory identities post-injury (Nochi, 1998). As a result, many experience increasing social isolation, develop a range of mental illnesses, and fall short of the improvements in psychosocial functioning that may have been possible had they received the necessary support (Lezak et al., 2004; Thomas, 2004). In addition, recent research suggests that adjustment following ABI is a continuous and cyclical process, not a static arrival at a state of rehabilitation as once thought (Muenchberger, Kendall, \& Neal, 2008).

Considering the aforementioned potential changes, it is no surprise that for individuals who can remember their pre-injury selves and have the capacity for selfawareness, experiences of identity confusion is an extremely common occurrence (Myles, 2004).

\section{Why has identity typically been an overlooked component of rehabilitation following ABI?}

Haslam et al. (2008) claim that rehabilitation plans following ABI are beginning to expand their recognition of the need for services beyond acute medical care, and family and community-based services are emerging as important sites for attention postinjury. This is important when considering that identity change for most individuals only becomes an issue post-hospitalization, long after many of their physical wounds have 
healed and direct medical care is no longer readily available (Muenchberger et al., 2008).

Another reason why identity has been overlooked in the rehabilitation literature has to do with a belief that the subjective experience of ABI survivors is not a reliable or important source of information when evaluating progress (Gracey et al., 2008). Instead of considering the perspectives of survivors, outcome measurements such as scores on depression indices and income levels were seen as indicative of rehabilitation progress (Johnston, Goverover, \& Dijkers, 2005). According to Crisp (2004, as cited in Nochi, 1998), most studies have approached the topic of subjective experience from a medical or neuropsychological point of view and an individual's perspective is rarely valued.

Furthermore, despite research focusing on the self of people with acquired brain injuries, the self is still largely "regarded as a dependant variable of a brain injury" (Nochi, 1998, p. 869).

Perhaps due to advancements in qualitative methodologies, or a more accurate appreciation of the importance of subjective experience in rehabilitation for ABI survivors, there has been a shift in focus away from primarily neuropsychological and medical perspectives. Brown, Gordon, and Haddad (2000) point out that subjective quality of life for ABI survivors is emerging as a key variable in predicting rehabilitation outcomes. This has stirred increasing interest in the experiences of loss of identity for ABI survivors and the resulting impact on their lives. There have been numerous studies indicating the drastic impact that ABI has on a person's sense of self (Muenchberger et al., 2008; Nochi, 1997, 1998). Furthermore, a New York based holistic rehabilitation program, established in 1978 by Yehuda Ben-Yishay, was the first of its kind to seriously consider the psychosocial aspects of rehabilitation and focus specifically on reconstructing an individual's identity (Ben-Yishay, 2008). Largely ignored for many years, Ben-Yishay's holistic rehabilitation program is now being recognized as a superior example of an efficacious and comprehensive clinical intervention and is being replicated all over the world (e.g., Coetzer, 2008; Sarajuuri \& Koskinen, 2006).

\section{Why is identity an important component of rehabilitation?}

As Moldover, Goldberg, and Prout (2004) point out, "[ABI] is not only a neuropathological event but also a unique psychological process with profound implications for identity development" (p. 151). They go on to describe ABI as resulting in a severing of the continuity of who the person is, which has a profound impact on one's sense of self. The authors view ABI as a developmental process that requires a grieving period in which the old identity can be mourned and the construction of a new identity can occur. Cantor et al. (2005) claim that after ABI, "the injured person lives with two images of the self: 'who I am now' and 'who I was before injury'" (p. 531). These differing conceptions of self can be highly distressing, leading to affective disorders such as anxiety and depression and severely restrict the possibility of successful rehabilitation post-injury (Cantor et al., 2005).

In 2005, Vickery, Gontkovsky, and Caroselli investigated the intra-personal variable of self-concept, or positive self-identity, for ABI survivors and its association 
with subjective experiences of quality of life. Their study confirmed previous research suggesting that development of positive self-identity was predictive of higher levels of quality of life post-injury. Cloute, Mitchell, and Yates (2008) expand on this idea by explaining that despite achievements in significant rehabilitation goals (e.g., work, financial security, mobility), individuals who experience a sustained disruption to their identity are more likely to experience mental health concerns (e.g., depression, anxiety), lack a positive sense of the future, and are less likely to report a good quality of life.

It has also been shown that identity disruptions are associated with increased difficulties in forming and maintaining social networks (Hoofinen, Gilboa, \& Vakil, 2003; Engberg \& Teasdale, 2004). According to Haslam et al. (2008), maintenance of one's social identity is predictive of well-being following ABI. Furthermore, in his latest study, Nochi (2000) investigated the self-narratives of ABI survivors and found that "people with ABI are not coping with their changed lives just by 'accepting' their injuries. Instead, they seem to ultimately revise their self-narratives"(p. 1799). Muenchberger et al. (2008) suggest that for survivors of ABI to experience a sense of control and fulfillment in their lives, they need to make sense of the profound changes associated with their injuries and come to some understanding regarding their processes of identity transition following injury. This is consistent with other literature that found ABI survivors ability to cope with changes in identity were predictive of anxiety levels (Dewar \& Gracey, 2007). Considering these points, it is clear that understanding and adequately addressing identity disruptions is a crucial component of the rehabilitation process following $\mathrm{ABI}$.

My intention up to this point has been threefold:

1. To provide an overview of acquired brain injury;

2. To demonstrate how advancements in knowledge regarding ABI have allowed identity to take its rightful place on the agenda of researchers and practitioners; and

3. To make a case that identity is a crucial factor in the rehabilitation process following acquired brain injury.

The next part of this review will examine a selective sample of the biological, psychological, and psychosocial accounts of the causes of identity change and the clinical interventions cited in the literature. This will also involve a clarification of the nomenclature, as this is necessary and has yet to be done.

\section{How do biological, psychological, and social perspectives explain experiences of identity change?}

As noted by Yeates et al. (2008), biological explanations of personality change following ABI have traditionally been derived from individualized notions of personality such as Eysenck (1967), where alterations to neurological structures are directly linked to changes in personhood. From this perspective, personality traits are unique to the individual, stable, biologically-based and located in the brain. Thus, when an injury occurs to a person's brain, personality change is associated primarily with damage to specific cortical areas. Although this conceptualization of a direct brain-mind connection 
has been commonplace, at least in the West, Yeates et al. (2008) point out that social neuroscientists, psychologists, and cultural theorists have been contributing convincing evidence suggesting that perhaps subjective and intersubjective factors contribute to the personality changes experienced by ABI survivors. They claim that this offers clinicians a way out of the determinism of personality trait theorists (which offers a dead end in terms of rehabilitation) and proposes a more complex and integrative understanding of these changes. However, there still exists much controversy in the literature, largely due to epistemological and ontological reasons. This helps explain why different terms such as "personality", "self-concept", "self-narratives", and "identity" are used to describe changing personhood following ABI. It is apparent that theoretical foundations of what constitutes the "self" dictate the terms used to describe this phenomenon. It is hoped that an in-depth examination of the biological, psychological, and social literature will provide additional clarification.

\section{Social Neuroscience Perspective}

It is well established that damage to the orbitofrontal and ventromesial frontal cortical areas (prefrontal brain systems) are associated with lack of social insight and executive dysfunctions such as altered emotional processing, decision-making, disinhibition, and euphoria, often contributing to "personality change" that is disruptive to the healthy maintenance of social relationships (Mathiesen \& Weinryb, 2004; Namiki et al., 2008). However, recent advancements in social neuroscience are expanding our understanding of connections between cortical damage, social interaction, and personality change. More specifically, damage to portions of the brain connected to socio-affective processes is being explored. Summarizing the socio-affective neurological processes involved in a one-to-one encounter, Yeates et al. (2008) claims that key parts of the brain (inferior parietal and anterior cingulated networks) are involved in the concurrent process of (a) predicting the intentions of others, (b) aligning to another's subjective experience, and (c) influencing the subjectivity and behaviour of the other person. These cortical areas, also commonly referred to as "mirror neurons", seem to be crucial components in aligning to another's experience and "connecting".

Furthermore, perceptions of one's internal emotional experiences have been shown to be compromised following damage to areas in the limbic system and frontal lobes, resulting in difficulty perceiving such emotions as fear and anger (Park et al., 2001), sadness (Blair \& Cipolotti, 2000), disgust (Calder, Keane, Manes, Antoun, \& Young, 2000), and experiencing and expressing empathy (Lezak et al., 2004). Yeates et al. (2008), commenting on the results from recent social neuroscience literature claim that "[now] it is possible to specify how both subjective experience and social interactions can be differentially altered through neuro-anatomical damage" (p. 571). This recognition of the interchange between social and neurological processes is an important step towards deepening traditional individualized neurological accounts that isolate personality primarily in the person's brain and fail to recognize interactions with social processes.

There also is growing literature surrounding memory impairment and the experience or judgment of personality change. Fotopoulou (2008) reminds us that connections between memory and personality have long been discussed in the history of 
philosophy by such prominent thinkers as John Locke (1690) and William James (1890/1999). Advancements in cognitive-neuropsychological understanding are again drawing attention to the connections between memory and personality as an important area for further inquiry. Moreover, survivors of ABI who are experiencing gaps in shortor long-term memory appear to have difficulty maintaining a coherent and continuous narrative of their experience (Nochi, 1998). Explaining this further, Yeates et al. (2008) state that, "a loss of autobiographical memory as a part of retrograde amnesia removes large portions of personal history and can thus devastate narratives about the self, while antegrade amnesia can also interfere with personal narratives by interrupting with their construction" (p. 571).

A recent study conducted by Fotopoulou (2008), sought to expand on the connection between memories and their influence on the processes of personhood following ABI. Drawing on current neuroscientific literature and case studies, attention was drawn to the process of confabulation (false memories produced without conscious knowledge of their falsehood) and how ABI survivors appear to draw on such confabulations, altering perceptions of themselves. Fotopoulou (2008) claims that, "lost or disrupted memories may lead to the experience of a discontinued and fragmented identity, over and above other post morbid difficulties and concerns. They instead construct false 'selves', potentially insisting they are somewhere else, doing something else and having a different profession and family" (p. 548).

In accounts of memory and personality in both Yeates et al. (2008) and Fotopoulou (2008), an attempt to merge neuroscience literature with material from the "narrative turn in psychology" (Mahoney, 2003) was used to support their claims. However, sufficient attention was not given to the latter and resulted in the introduction of terms such as identity and self-narrative without thorough explanations of the theoretical grounding underpinning this "narrative self". For example, no mention of the relational and political processes involved in the creation and maintenance of particular self-narratives were offered (e.g., Gergen, 1985; Mahoney, 2003; White \& Epston, 1990). These ideas are taken up further in the section below on social processes and identity.

This section attempted to present advancements in social neuroscience that have been helpful in explaining changes in personality following ABI. There was an intentional omission of individualized biological accounts, as social neuroscience is posing a serious challenge to these claims and offers more hope in the realm of effective intervention. The term "personality change" is most commonly used in this biologicalmaterialist paradigm, however it was noted that in some accounts, attempts at incorporating a narrative conception of "self" was included. Moving from biological explanations, the relevant cognitive-psychological literature will be explored.

\section{Cognitive-Psychological Models}

The literature regarding psychological models of change following ABI is vast and divided. Descriptions such as changes in ego, self-concept, self-schemas, and selfconstructs are indicative of how these theorists are conceptualizing the location of personhood. Within these accounts, there appear to be epistemological tensions resulting 
in different researchers failing to acknowledge each other's work. For example, research on schematic-information processing models and cognitive-behavioural approaches fail to mention constructivist and phenomenological literature and vice-versa. Common across all these accounts is recognition that an alteration to the subjective processes in which information about oneself is stored and constructed governs experience or perception of self in specific contexts (Yeates et al., 2008). A selective account from each of these approaches will be utilized to investigate the topic of concern from a psychological angle.

\section{Cognitive-behavioural (Self-concept)}

Ylvisaker and Feeney's (2000) theoretical paper was one of the first cognitive accounts attempting to explain changes to self-concept ${ }^{3}$ following ABI. They draw on an interacting cognitive subsystems (ICS) approach, suggesting that schematic mental models of the self are constructed through cognitive processes that rely on the relationship between recurring experiences and their associated emotional states and behaviours. More specifically, they argue that changes in self-concept are tied to the novel constructions of schematic models of the self, triggered automatically by problematic stimuli that are associated with negative emotional states and socially adverse behaviours. Thus, biological changes following brain injury result in alternate self-coding and can explain changes in self-conception. Although, their theoretical ideas were supported through anecdotal evidence and case studies, it marks the beginning of psychological accounts of self-concept change following ABI.

Expanding on these ideas, Myles (2004) employs Relational Frame Theory (RFT), a modern behavioural approach to language and cognition, to investigate selfconcept changes following ABI. According to RFT, there exist three distinct senses of self that can be directly experienced by humans: (a) the conceptualized self, (b) self as an ongoing process of verbal knowing, and (c) self as context (Myles, 2004). Drawing on the extensive work of Hayes (e.g., 1994), the originator of RFT, Myles (2004) presents the conceptualized self as "the network of verbal self-relations that develops as a person repeatedly applies categorical concepts to her behaviors" (p. 493). This is very similar to the "self concept" described previously by Ylvisaker and Feeney (2000), as it involves mental representations of "self" that are constructed based on relationships between experiences and how these were interpreted, allowing for a cohesive self-conception. However, the conceptualized self is seen as one component of the experience of self. The second is self as ongoing process of verbal knowing (self-awareness), which according to Hayes (1994) is "a fluid, dynamic process of knowing one's own flow of experiences" (as cited in Myles, 2004, p. 493). The essence of this self is the private subjective experiences that comprise one's psychological content such as emotions, thoughts, and memories. The third sense of self is the self as context, which appears in early childhood with the development of a sense of perspective. It is the place from which the person experiences the world that never changes and is never lost, while consciousness remains.

\footnotetext{
${ }^{3}$ Identity loss and personality change have been used interchangeably to describe the experience of a disparity between how the survivor of an ABI experiences themselves post-injury, compared to pre-injury. Considerable attention will be devoted below to clarifying the differences between these terms and their associated epistemological underpinnings.
} 
"It is a stable, enduring sense of self that is not dependent on the nature of the content that comprises one's ongoing flow of psychological experience (Hayes \& Gregg, 2001, as cited in Myles, 2004, p. 494).

Typically, the conceptualized self dominates over the other two selves. People tend to identify with their psychological content rather than the context from which they experience it. However it is pointed out that some practices (e.g., meditation) can increase a person's awareness of and identification with, self as context, and this is often described as a spiritual or transcendent experience (Myles, 2004).

Myles (2004) argues that "loss of self" following injury is connected to a "crisis of the conceptualized self" (p. 494). More specifically, he makes the straightforward claim that loss of self is largely a verbal and relation process where persons' experiences of themselves as "not the same" is due to conscious awareness of the inconsistencies between post-injury functioning and pre-injury conceptualized self. Myles (2004) also points out the potential for negative outcomes such as emotional distress and denial: "If the survivor's pre-injury self-concept is positively evaluated by her, any post-injury changes in functioning that are inconsistent with it will very likely lead to negative evaluations, both of those changes and of the resulting new self-concept" (p. 494).

The claims put forth by Myles (2004) are helpful in expanding the work of Ylvisaker and Feeney's (2000) investigation of the "self", as well as providing RFT as the theoretical basis for changes in self-concept following ABI. These claims are consistent with Cantor et al.'s (2005) adaptation of self-discrepancy theory, which proposes that emotional distress following loss of self is due to tensions between preinjury and post-injury conceptions of self. However, anecdotal evidence and case studies were used to support the theoretical claims being put forward. Thus, these arguments are to be cautiously approached and perhaps used as theoretical guides for further empirical research on the cognitive aspects of changes to self-concept.

\section{Constructivist (self-constructs)}

Constructivism is a branch of psychology that is interested primarily in human meaning-making processes, which constructivists claim are central to experiences of personhood. Much of what constitutes the roots of constructivism comes from the work of George Kelly and his personal construct psychology (PCP). (For a full account of the history of constructivism see Mahoney, 2003). Summarizing the work of Kelly (1955/1991), Gracey et al. (2008) explain the process of psychological representation of external reality from a PCP perspective:

Each of us actively makes sense of or interprets all the things we encounter... and repeated interpretations of experiences are made on the basis of, and from dichotomous constructs that become hierarchically organized. It is proposed that the logic of ascribing meaning via the application of unidimensional concept (e.g. pain, love) is flawed as these concepts only make sense in relation to their absence or opposite (pain-free, hate). Sets of constructs will develop for specific sets of situation, people or other aspects of reality. This means that for a given 
encounter our sense making is restricted by constructs formed from past encounters with people and relationships. (p. 631)

This quote is helpful in identifying how research from a constructivist perspective is similar to and differs from the work presented earlier from a behavioural-analytic perspective. There is congruence on the point that people make sense of themselves through mental interpretations of their experiences, yet constructivist accounts emphasize the relations and contrasts between concepts as crucial in the process of making meaning.

In an attempt to map out a person's constructs, some constructivist researchers have devised rigorous, quantitative methods that are highly sensitive to the subjectivity of the individual. This allows for a detailed account of how one makes sense of or construes other people and repeated ratings over time and can be used to measure change (Gracey et al., 2008). Such an approach was utilized by Gracey et al. (2008) in their attempt to "find out the salient patterns of self-construing engaged in by individuals when making sense of changes after brain injury" (p. 632). Results suggest that following brain injury, individuals may be especially concerned with personal meanings and feelings associated with activity, both practical and social. For example, belonging, capability, the extent to which activities "reinforce who I am", or how the activity helps to make someone "feel part of things", were all found to be pertinent factors. Moreover, their data highlights that existential concerns also feature strongly in the process of self-construal after injury and that there is a wide range of ways in which people make sense of themselves.

This study represents the first attempt to elicit and analyze the personal constructs of survivors of ABI. However, it is not without its weaknesses. In particular, a selective and small sample was used limiting the generalizability of their findings and the robustness of the constructs identified. In addition, little consideration was given to the extent of brain damage that participants had and how this might have influenced their capacity to create constructs. Nonetheless, the work of Gracey et al. (2008) is an impressive contribution to constructivist understandings of changes to self-constructs following $\mathrm{ABI}$.

Another notable study from a phenomenological qualitative perspective was conducted by Muenchberger et al. (2008) in which an attempt to create a broader understanding of the development of self, following injury, was undertaken. This complements the work by Gracey et al. (2008) as the phenomenological paradigm is also centrally concerned with individual meaning and the changes in self-construction over time are examined.

Muenchberger et al. (2008) found that the process of (re)constructing self following injury is a dynamic affair that involves balancing between the phases of contraction and expansion of self and tentative equilibrium. Contraction of self was explained as experiences of sense-making when the self "appears characterized by internal and external pressures to conform to a desired state" (p. 986) and where limited opportunities for individualization, creativity, or the development of self-confidence exist. Examples of contraction periods involved experiencing a lack of a continuous sense of self, a focus on daily functioning, a sense of being different, and a reliance on others. 
Conversely, Muenchberger et al. (2008) found that periods of expansion of self were marked by feelings of being given a second chance at life, and an "emerging focus on pursuing an alternate life role and redefining personal goals" (p. 987). Examples include experiencing a greater sense of being able to cope, an ability to understand the need for acceptance of change, and the benefits of interdependence and working towards goals. Finally, these authors also noted that the tentative balance phase was likened to the concept of liminality, which "describes both a state of being in 'limbo' and a process in which individuals find themselves between former and future states" (p. 990). Examples of how tentative balance was experienced were: (a) forward but fragile progression; (b) self-doubt; (c) uneasy sense of past, present, future; and (d) tensions relating to compliance and need for control.

The current findings provide a broader conceptual understanding of the processes of reconstruction of self for a selective sample of ABI survivors. It highlights the profound disruptions to "self" following injury and presents a transitional account where periods of expansion, contraction, and relative stability of self are experienced. These conclusions challenge accounts of reconstruction of self as being linear and progressive and instead suggest cyclical and ongoing processes. Furthermore, these findings contest the literature that positions survivors as passive recipients of their biology. Instead, it demonstrates how survivors are actively involved in the interpretation of their symptoms, which supports similar claims made by other researchers (e.g., Nochi, 1998).

This section examining the literature from a psychological perspective attempted to clarify some of the different epistemological positions functioning within this perspective. Common to all these accounts was a privileging of individual subjectivity in the construction of reality. This was indicated in the use of terms such as self, selfconcept, and self constructs to describe notable changes pre- and post-injury for survivors of ABI.

\section{Social/Intersubjective Accounts}

There is a growing body of literature examining intersubjective accounts of meaning-making and identity construction following $\mathrm{ABI}$. The language involved in descriptions of pre- and post-injury, social meanings, and discourses are emerging as important contextual parameters in survivors' post-injury sense-making and identity formation (Yeates et al., 2008). Terms such as narratives and identity tend to be frequently used in these accounts of changes to personhood post-injury, signifying the recognition of a multiplicity of factors involved in constituting the self.

A number of studies have taken an interest in the narratives of survivors. The narrative turn, as introduced earlier, was articulated in Polkinghorne's (1988) seminal work, Narrative Knowing and the Human Sciences. This book had a profound influence on bringing forth the importance of narratives for organizing and understanding human experience. Polkinghorne makes a strong case for the centrality of meaning-making processes in human experience and the role that narratives play in organizing these experiences into temporally meaningful episodes. Embedded in the language of narratives are a systematic view of human experience and an understanding of multiple 
realities versus one concrete truth. Summarizing the importance of narratives, Polkinghorne (1988) argues:

Narratives are a scheme by means of which human beings give meaning to their experience of temporality and personal actions. They provide a framework for understanding the past events of one's life and for planning future actions. They are the primary scheme by which human existence is rendered meaningful. Thus, the study of human beings by the human sciences needs to focus on the realm of meaning in general, and on narrative meaning in particular. (p. 11)

At first glance, narrative inquiries can appear to be solely a subjective and individualized process. However, the language available to tell the stories of our lives is highly reliant on the culture and power relations in which we are embedded. Michel Foucault's large body of work (e.g., 1969, 1977) has been instrumental in our understanding of how power relations influence the creation, maintenance, and authority of different regimes of knowledge or discourses. A more detailed review of his work is outside the scope of this paper, yet it is crucial in our understanding of how narratives are a psychosocial process. Furthermore, the work of narrative therapists such as Michael White and David Epston (1990) have extended Foucault's work by deciphering the numerous ways in which intersubjective processes are involved in the authoring of people's identities. In turn, they have created therapeutic interventions, such as communities of concern and therapeutic letter writing campaigns, to assist people in resisting dominant discourses and facilitate the re-authoring of preferred stories.

In a series of studies, Nochi $(1997,1998,2000)$ examined the self-narratives of survivors following ABI. In doing so, he demonstrated the reliance of the ABI survivor on the broader social contextual dimension. In his 1997 work, he identified a "void" that is present in many survivors' self-narratives, largely due to memory problems interfering with their recollection of their accidents and portions of their recovery. Recognizing that many survivors carry with them something unknown, Nochi (1997) remarks that "[ABI] is a real crisis of the self" (p. 18) as the void in past memories serves as a barrier to selfunderstanding. This description of a void is very similar to the above concept of liminality introduced by Muenchberger et al. (2008). Furthermore, Cloute et al. (2008) found that survivors' attempts to retell and fill their lost memories are often challenged by the interpretations of close relatives and friends, highlighting the interpersonal components of re-authoring processes.

In his 1998 study, Nochi identified three areas of "loss of self" following ABI: (a) loss of self in relation to pre- to post-injury comparison, (b) loss of self in the eyes of others, and (c) discontinuity of identity through lost or disrupted memories. The first and third theme support much of the work introduced above, yet the second theme highlights the importance of other people's opinions regarding identity change. This was supported by the work of Weddell and Legget (2006, as cited in Yeates et al., 2008) as they found that while social neuropsychological factors did predict relatives' and friends' judgments of identity change, it was in fact the level of psychological distress in both survivors and relatives that was most predictive. 
In his latest work, Nochi (2000) focuses on narratives from survivors who have managed to reconstruct a coherent self-narrative and who felt "at ease" with their situation. He concludes that successful developments of self-narratives need to occur, "in interaction with other people, society, and culture" (p. 1802), as opposed to isolated rehabilitation. This may involve reorganizing interpersonal relationships and environments so that they support newly developing and preferred self-narratives.

The impact of social relations on identity was taken up by Haslam et al. (2008) in their investigation of stroke survivors, which also provides the first quantitative support for the importance of social processes in recovery. Drawing on social identity theory which emphasizes, "the importance of both social identities in general and social continuity in particular for well-being" (p. 672), they found that maintenance of group membership predicted well-being after a stroke. These findings highlight the role of social continuity in facilitating positive rehabilitation outcomes. Furthermore, it brings to light the importance of group membership and social identity in neuropsychological rehabilitation, rather than personal identity.

The work of social constructionists such as Ken Gergen (1991) have been instrumental in our understanding of how social relations influence the creation of reality. This social constructionist turn "emphasizes subjectivity, language, social processes and the importance of understanding individuals as actively constructing meaning in the context of interactions with others" (Gracey \& Ownsworth, 2008, p. 522). From a social constructionist perspective, there is no individual identity, but instead a co-constructed intersubjective relational identity that is dependent on the social practices (e.g., creation of language, knowledge, processes of interpretation) that bring them into being (Gergen, 1985). From this perspective, "the mind becomes a form of social myth; the self concept is removed from the head and placed within the sphere of social discourse" (Gergen, 1985 , p. 271). This does not mean that people cannot relate to themselves, or have a "stable" sense of self. However, it does recognize that all accounts of a self are interwoven within the culture and relations that one is embedded within.

Relational conceptualizations of identity have been emerging in recent neuropsychology and rehabilitation literature. In a recent study, Cloute et al. (2008) employed a social constructionist methodology to investigate the question of construction of identity following ABI. They were interested in how the language and interactions from dominant medical services influenced the creation of self following ABI. Their discursive approach reveals that particular attention needs to be paid to how people are positioned and identified, particularly by the medical community. For example, binaries such as patient-expert, abnormal-normal, and sick-healthy often implicitly function in medical discourse and have a tremendous impact on how a person understands him or herself. In the Cloute et al. (2008) study, it was found that "medical model referencing left participants seemingly dependent upon the active interpretations of expert professionals and specialist services" (p. 665), leaving little room for survivors and their families to construct themselves in alternate ways. This example highlights the dynamic and social aspects of identity construction and supports other research that has investigated the passive positioning of people with disability and illness when seeking medical support (Oliver, 1990). 


\section{Rebuilding a Coherent Sense of Self: Clinical Interventions}

Reconstructing identity following ABI represents a challenge on many fronts. As demonstrated, the biological, personal, familial, and community levels are all implicated to some degree. Table 2 presents the different therapeutic approaches, found in the literature, arranged based on theoretical area of inquiry. 
Table 2. Summary of interventions for "personality change" based on biological, psychological, and social accounts.

\begin{tabular}{|c|c|}
\hline Social Neuroscience: & $\begin{array}{l}\text { Socio-affective (Yeates et al., 2008) } \\
\text { - } \quad \text { Training to identify emotional expression from facial, bodily, and } \\
\text { conversational cues. } \\
\text { Social skill training aimed at teaching social responses and reading social } \\
\text { norms. } \\
\text { Cognitive neuropsychological (Yeates et al., 2008) } \\
\text { - } \quad \text { Problem-solving frameworks addressing executive functioning, and emotional } \\
\text { regulation. } \\
\text { Creating memory and autobiographical aids. (e.g., keep newspapers and } \\
\text { doctors' notes from the time of the accident.) } \\
\text { Confabulations (Fotopoulou, 2008) } \\
\text { Liaising with significant others to understand and explain how confabulations } \\
\text { are cognitively and motivationally constructed. } \\
\text { Discouraging rehabilitation staff from confirming or contradicting patients' } \\
\text { confabulations. } \\
\text { Using individual sessions to progressively explore the subjective meaning of } \\
\text { confabulations and provide non-threatening feedback. } \\
\text { Discussing confabulation in the third person. }\end{array}$ \\
\hline Cognitive-Psychological: & $\begin{array}{l}\text { Interacting Subsystems Approach (Ylvisaker \& Feeney, 2000) } \\
\text { - } \quad \text { Reconstruction of self-concept through appealing metaphors. } \\
\text { Concrete organization of self-concept through models using graphic } \\
\text { organizers. } \\
\text { Desensitization to prevent dysfunctional emotional reactions. } \\
\text { - } \quad \text { Improptance and Commitment Therapy (Myles, 2004) } \\
\text { acceptance of the changes in functioning and self-concept. } \\
\text { Client-focused and Value driven (Muencherger et al., 2008) } \\
\text { Provide a dynamic and flexible context in which individuals can devise } \\
\text { strategies to move forward and expand amidst the cycles of expansion, } \\
\text { contraction, and liminality. } \\
\text { Meaning Centred therapy (Gracey et al., 2008) } \\
\text { Focus on changing personal meanings and feelings associated with post- } \\
\text { injured self and activities. }\end{array}$ \\
\hline Psychosocial: & $\begin{array}{l}\text { Narrative Focused (Nochi, 1997, 1998, 2000) } \\
\text { - } \quad \text { Focus on reconstructing self narratives. } \\
\text { - } \quad \text { Recognize that clients have more than one narrative about themselves and } \\
\text { Dearch for the preferred stories. } \\
\text { modify environments if needed. } \\
\text { Teach individuals and family members how to disseminate preferred } \\
\text { - } \quad \text { Darratives about themselves. } \\
\text { Discursive Positioning (Cloute et al., 2008) } \\
\text { - Facilitating the co-construction and re-authorship of empowering and } \\
\text { - } \quad \text { Facilitate diaries written by the family and the injured party. } \\
\text { Become aware of referencing medical discourse and the potential for } \\
\text { - } \text { dependency. This might involve referencing more empowering repertoires. } \\
\text { Practitioners undertake a process of self-reflection in order to become } \\
\text { reflexively engaged in their work. } \\
\text { - } \quad \text { Assist individuals to develop meaningful social roles in the community. } \\
\text { Support the maintenance and facilitation of social identification. }\end{array}$ \\
\hline
\end{tabular}

The examples provided in Table 2 represent only a small fraction of the different rehabilitation strategies devised to address issues of identity change following ABI. However, addressing identity is usually seen as only a side concern for most rehabilitation professionals. The introduction of the holistic neuro-rehabilitation model 
(Ben-Yishay, 2008) was the first program to focus on reconstructing shattered identities. Furthermore, it attempts to provide a "therapeutic community setting" (p. 514), where integration of these approaches are offered to both individuals and their families. These intensive, short-term programs have recently been taken into the communities and offered over a longer duration with less intensity. Outcome data appears to be promising, but research is still in its early stages (Coetzer, 2008). In agreement with Yeates et al. (2008), interventions that consider the interacting and interdependent casual mechanisms across neurological, psychological, and psychosocial levels offer the most promising rehabilitation outcomes for survivors and their families.

\section{Gaps in the Literature}

In addition to the critiques and concerns presented above, a crucial component largely absent from the literature is the ethical dimension of supporting the rehabilitation of someone with ABI in the reconstruction of their identity. As Little (2005) points out, ethical practice cannot be separated from political spheres. Thus, the way we conduct ourselves in accordance with our ethics is a political act. This requires reflexive practice, as simply having the desire to help, is not a sufficient condition to absolve the potential for harm. These ideas were touched on in the work of Cloute et al. (2008), where practitioner reflexivity was recommended, yet it still remains an important area for further exploration. White (2007) offers some helpful insights in her articulation of a praxis-oriented approach to child and youth care. She defines praxis as, "an ethical, selfaware, responsive and committed action" (p. 1). Perhaps rehabilitation professionals would benefit from exploring this literature more thoroughly.

Another important area that appears to be neglected is the manner in which rehabilitation professionals can engage with family and community members regarding matters of identity. Lezak et al. (2004), points out that "family members are more likely to find the physical deficits acceptable to discuss and deal with than the emotionalpersonality problems" (p. 183). Thus, although the importance of interpersonal aspects has been emphasized, further attention regarding strategies to effectively include family and community members in the rehabilitation process is warranted.

Finally, finding ways to integrate the diverse epistemological understanding and interventions presented is necessary to ensure that rehabilitation professionals have the most complete account possible. Wilber's (1995) integral framework might be one possible method by which to merge these seemingly disparate parts.

\section{Conclusion}

It is clear that biological, psychological, and social components are involved in the experiences of "personality change" or identity loss following ABI. Having an understanding of these different perspectives is crucial in approaching the most complete understanding of this phenomenon. However, it is also evident that in doing so, particular epistemological tensions and contradictions emerge, indicated by the variety of terms being used to describe the experience of personality change. It is hoped that by uncovering the underpinning theoretical foundations, a clearer understanding of their origins has been achieved. Furthermore, it is hoped that an exploration of the subjective 
and intersubjective processes involved in the construction of identities post-injury demonstrates the "paradigm shift" (Kuhn, 1962) taking place towards more diverse accounts and away from traditional biologically dominated explanations. Movement towards integrated and interdisciplinary theories are equipping practitioners with a wide spectrum of strategies which they can use to support individuals and their families through the processes of (re)constructing, (re)discovering, and (re)claiming their lost identities.

\section{References}


B.C. Brain Injury. (2009). B.C. Brain Injury Association homepage. Retrieved December 9, 2009, from

$<$ http://www.bcbraininjuryassociation.com/acquired.php $>$.

Ben-Yishay, Y. (2008). Foreword. Neuropsychological Rehabilitation, 18(5/6), 513-521.

Ben-Yishay, Y., Rattok, J., Latkin, P., Piasetsky, E. D., Ross, B., Silver, S., et al. (1985). Neuropsychologic rehabilitation: Quest for a holistic approach. Seminars in Neurology, 5, 252-259.

Blair, R., \& Cipolotti, L. (2000). Impaired social response reversal: A case of acquired sociopathy. Brain Injury, 123(6), 1122-1141.

Brown, M., Gordon, W. A., \& Haddad, L. (2000). Models for predicting subjective quality of life in individuals with traumatic brain injury. Brain Injury, 14(1), 5-19.

Calder, A. J., Keane, J., Manes, F., Antoun, N., \& Young, A. W. E. (2000). Impaired recognition and experience of disgust following brain injury. Nature Neuroscience, 3, 1077-1078.

Cantor, J. B., Ashman, T. A., Schwartz, M. E., Gordon, W. A., Hibbard, M. R., Brown, M., et al. (2005). The role of self-discrepancy theory in understanding posttraumatic brain injury affective disorders: A pilot study. Journal of Head Trauma Rehabilitation, 20(6), 527-543.

Cloute, K., Mitchell, A., \& Yates, P. (2008). Traumatic brain injury and the construction of identity: A discursive approach. Neuropsychological Rehabilitation, 18(5), 651-670.

Coetzer, R. (2008). Holistic neuro-rehabilitation in the community: Is identity a key issue? Neuropsychological Rehabilitation, 18(5/6), 766-783.

Condeluci, A., Ferris, L., \& Bogdan, A. (1992). Outcome and value: The survivor perspective. Journal of Head Trauma Rehabilitation, 7(4), 37-45.

Corrigan, J. D., Bogner, J. A., \& Mysiw, W. J. (2001). Life satisfaction after traumatic brain injury. Journal of Head Trauma Rehabilitation, 16(6), 535-555.

Dewar, B. K., \& Gracey, F. (2007). "Am not was": Cognitive behaviour therapy for adjustment and identity change following herpes simplex encephalitis. Neuropsychological Rehabilitation, 17(4/5), 602-620.

Engberg, A. W., \& Teasdale, T. W. (2004). Psychosocial outcome following traumatic brain injury in adults: A long-term population-based follow-up. Brain Injury, 18(6), 533-545.

Eysenck, H. J. (1967). The biological basis of personality. Springfield, IL: Charles Thomas. 
Fotopoulou, A. (2008). False selves in neuropsychological rehabilitation: The challenge of confabulation. Neuropsychological Rehabilitation, 18 (5/6), 541-565.

Foucault, M. (1969). The archeology of knowledge. New York: Routledge.

Foucault, M. (1977). Discipline and punish: The birth of the prison. New York: Random House.

Gan, C., Campbell, K. A., Gemeinhardt, M., \& McFadden, G. T. (2006). Predictors of family system functioning after brain injury. Brain Injury, 20(6), 587-600.

Gergen, K. (1985). The Social constructionist movement in modern psychology. American Psychologist, 40(3), 266-275.

Gergen, K. (1991). The saturated self. New York: Basic Books.

Gracey, F., \& Ownsworth, T. (2008). Editorial. Neuropsychological Rehabilitation, $18(5 / 6), 522-526$.

Gracey, F., Palmer, S., Rous, B., Psailia, K., Shaw, K., O’Dell, J., et al. (2008). 'Feeling part of things": Personal construction of self after brain injury.

Neuropsychological Rehabilitation, 18 (5/6), 627-650.

Haslam, C., Holme, A., Haslam, A. S., Iyer, A., Jetten, J., \& Williams, H. W. (2008). Maintaining group memberships: Social identity continuity predicts well-being after stroke. Neuropsychological Rehabilitation, 18 (5/6), 671-691.

Hoofinen, D., Gilboa, A., \& Vakil, E. (2003). TBI 10-20 years later. Brain Injury, 15, 189-209.

James, W. (1890). The Principles of Psychology (2 vols.). New York: Henry Holt. Reprinted 1999. Bristol, UK: Thoemmes Press.

Johnston, M.V., Goverover, Y., \& Dijkers, M. (2005). Community activities and individuals' satisfaction with them: Quality of life in the first year after traumatic brain injury. Physical Medicine and Rehabilitation, 86, 735-745.

Kelly, G. A. (1955). The psychology of personal constructs. New York: Norton. Reprinted 1991. London: Routledge.

Kuhn, T. S. (1962). The structure of scientific revolutions. Chicago: Chicago University Press.

Landau, J., \& Hissett, J. (2008). Mild traumatic brain injury: Impact on identity and ambiguous loss in the family. Family Systems and Health, 26(1), 69-85.

Lezak, M. D., Howieson, D. B., Loring, D. W., Hannay, J. H., \& Fischer, J. S. (2004). Neuropsychological Assessment (4th ed.). New York: Oxford University Press.

Little, J. N. (2005) Feminist ethical development: From wonder woman to wondering 
woman. Child \& Youth Care Forum, 34(2), 111-126.

Locke, J. (1690). An essay concerning human understanding. London.

Mahoney, M. (2003). Constructive psychotherapy: Theory and practice. New York: Guilford Press.

Mathiesen, B. B., \& Weinryb, R. M. (2004). Unstable identity and prefrontal injury. Cognitive Neuropsychiatry, 9(4), 249-266.

Moldover, J. E., Goldberg, K. B., \& Prout, M. F. (2004). Depression after traumatic brain injury: A review of evidence for heterogeneity. Neuropsychology Review, 14, 143-154.

Muenchberger, H., Kendall, E., \& Neal, R. (2008). Identity transition following traumatic brain injury: A dynamic process of contraction, expansion and tentative balance. Brain Injury, 22(12), 979-992.

Myles, S. S. (2004). Understanding and treating loss of self following brain injury: A behavior analytic approach. International Journal of Psychology and Psychological Therapy, 4(3), 487-504.

Nochi, M. (1997). Dealing with the 'void': Traumatic brain injury as a story. Disability and Society, 12(4), 533-555.

Nochi, M. (1998). "Loss of self" in the narrative of people with traumatic brain injuries: A qualitative analysis. Social Science and Medicine, 46(7), 869-878.

Nochi, M. (2000). Reconstructing self-narratives in coping with traumatic brain injury. Social Science and Medicine, 51(12), 1795-1804.

Namiki, C., Yamada, M., Yoshida, H., Hanakawa, T., Fukuyama, H., \& Murai, T. (2008). Small orbitofrontal traumatic lesions detected by high resolution MRI in a patient with major behavioural changes. Neurocase, 14(6), 474-479.

Oliver, M. (1990). The politics of disablement. Tavistock, UK: Macmillian.

Park, N. W., Conrod, B., Rewilak, D., Kwon, C., Gao, F., \& Black, S. (2001). Automatic activation of positive but not negative attitudes towards traumatic brain injury. Neuropsychologia, 39, 7-24.

Polkinghorne, D. E. (1988). Narrative knowing and the human sciences. Albany, NY: State University of New York Press.

Sarajuuri, J. M., \& Koskinen, S. K. (2006). Holistic neuropsychological rehabilitation in Finland: The INSURE program - a transcultural outgrowth of perspectives from Israel to Europe via the USA. International Journal of Psychology, 41(5), 362370 . 
Thomas, M. (2004). The potential unlimited programme: An outdoor experiential education and group work approach that facilitates adjustment to brain injury. Brain Injury, 18(12), 1271-1286.

Vickery, C. D., Gontkovsky, S. T., \& Caroselli, J. S. (2005). Self-concept and quality of life following acquired brain injury: A pilot investigation. Brain Injury, 19(9), $657-665$.

Wilber, K. (1995). Sex, ecology and spirituality: The spirit of evolution. Boston: Shambhala.

White, J. (2007). Knowing, doing and being in context: A praxis-oriented approach to child and youth care. Child \& Youth Care Forum, 36(5), 225-244. doi:10.1007/s10566-007-9043-1

White, M., \& Epston, D. (1990). Narrative means to therapeutic ends. New York: W.W. Norton.

Yeates, G. N., Gracey, F., \& McGrath, J. C. (2008). A biopsychosocial deconstruction of 'personality change' following acquired brain injury. Neuropsychological Rehabilitation, 18(5/6), 566-589.

Ylvisaker, M., \& Feeney, T. (2000). Reconstruction of identity after brain injury. Brain Impairment, 1(1), 12-28.

David Segal is currently pursuing graduate studies with the School of Child and Youth Care, and is working towards becoming registered as clinical counsellor in BC. For over 10 years he has been working with children, youth and families primarily in an outdoor context. His current area of study includes the intersections of ecopsychology, identity construction and adventure therapy. When he is not working, he can often be found exploring the forests of Vancouver Island. 